\title{
GEOLOGIA REGIONAL E ESTRATIGRAFIA CRETÁCICA DO TRIÂNGULO MINEIRO
}

\author{
José Humberto Barcelos \\ Prof. Dr. do Dep. de Geologia Sedimentar - UNESP - Rio Claro
}

\begin{abstract}
RESUMO: Neste trabalho é apresentada uma revisāo litoestratigráfica das seqüências sedimentares cretácicas e a descriçāo e interpretação da Geologia Regional do Triângulo Mineiro. Buscouse evidenciar e esclarecer as relaçōes temporais das unidades litológicas, os sistemas deposicionais responsáveis e que se interagiram na deposiçāo e o seu lugar na evoluçāo da Bacia Sedimentar do Paraná.
\end{abstract}

Palavras-Chaves: revisāo litoestratigráfica, unidades litológicas, sistemas deposicionais.

ABSTRACT: A lithostratigraphic revision was carried on the Triângulo Mineiro Region in the crestaceous sequence. Special attention was focused to the Regional Geology based in new evidences about the temporal sequences of the lithologic units and the depositional environment sistems. Its role in the Parana Sedimentary Basin evolution are also emphasized.

Key Words: lithostratigraphic revision, lithologic units and depositional environments sistems.

\section{INTRODUÇÃO}

O Grupo Bauru (Cretáceo Superior) no Triângulo Mineiro tem sido alvo de diversos trabalhos de investigação, que possuem a característica comum de centrarem as suas descriçōes na região entre Uberaba, Uberlândia e - Alto do Paranaíba (Flexura de Goiânia), sem a menor dúvida constituída pela litoestratigrafia mais exótica desse grupo em toda a sua área de ocorrência na Bacia do Paraná.

Em conseqüência, apesar dessa área representar pequena parte do denominado Triângulo Mineiro, disseminou-se a crença generalizada de que o Grupo Bauru possuía características diferentes em todo o Triângulo Mineiro. Essa premissa foi desfeita por BARCELOS (1984) em trabalho de integraçāo regional das unidades do grupo, constatando que as unidades presentes no Estado de Sáo Paulo estendem-se por todo o Triângulo Mineiro, ocupando sua maior parte.

A interdigitação entre as litologias presentes no leste do Triângulo Mineiro e as que predominam nas demais áreas de ocorrência do Grupo Bauru é aqui descrita em maior detalhe, e as características da diversidade litofaciológica presente nessa margem da antiga bacia de sedimentaçāo é explicada através de suas características genéticas.

\section{CARACTERIZAÇÃO LITOESTRATIGRÁFICA E DISTRIBUIÇẨO GEOGRÁFICA}

As seguintes unidades litoestratigráficas do Grupo Bauru e a distribuição regional podem ser assim reconhecidas (segundo FULFARO \& BARCELOS, 1991 a e b) (Figura 1).

Formação Adamantina - A sua ampla distribuiçāo geográfica atribui-lhe também grande diversidade litológica, cujas fácies sedimentares podem ser relacionadas aos sistemas deposicionais fluviais meandrantes psamítico e pelítico. O primeiro é caracterizado por arenitos lenticulares com conspícuas estratificaçōes cruzadas de pequeno e médio porte, associados a sedimentos cíclicos síltico-argilosos (Membro São José do Rio Preto). O sistema fluvial meandrante pelítico, com sedimentaçāolacustre associada, está restrito ao Estado de São Paulo, sendo constituído por arenitos argilosos e siltitos, apresentando localmente arenitos lenticulares com estratificaçōes cruzadas de pequeno porte (Membro Araçatuba).

Formação Uberaba - Constituída por rochas epiclásticas (arenitos tufáceos associados a siltitos, argilitos, arenitos conglomeráticos e conglomerados arenosos. A sua distribuiçāo restringe-se ao Estado de Minas Gerais (Triângulo Mineiro e Alto Paranaíba). 


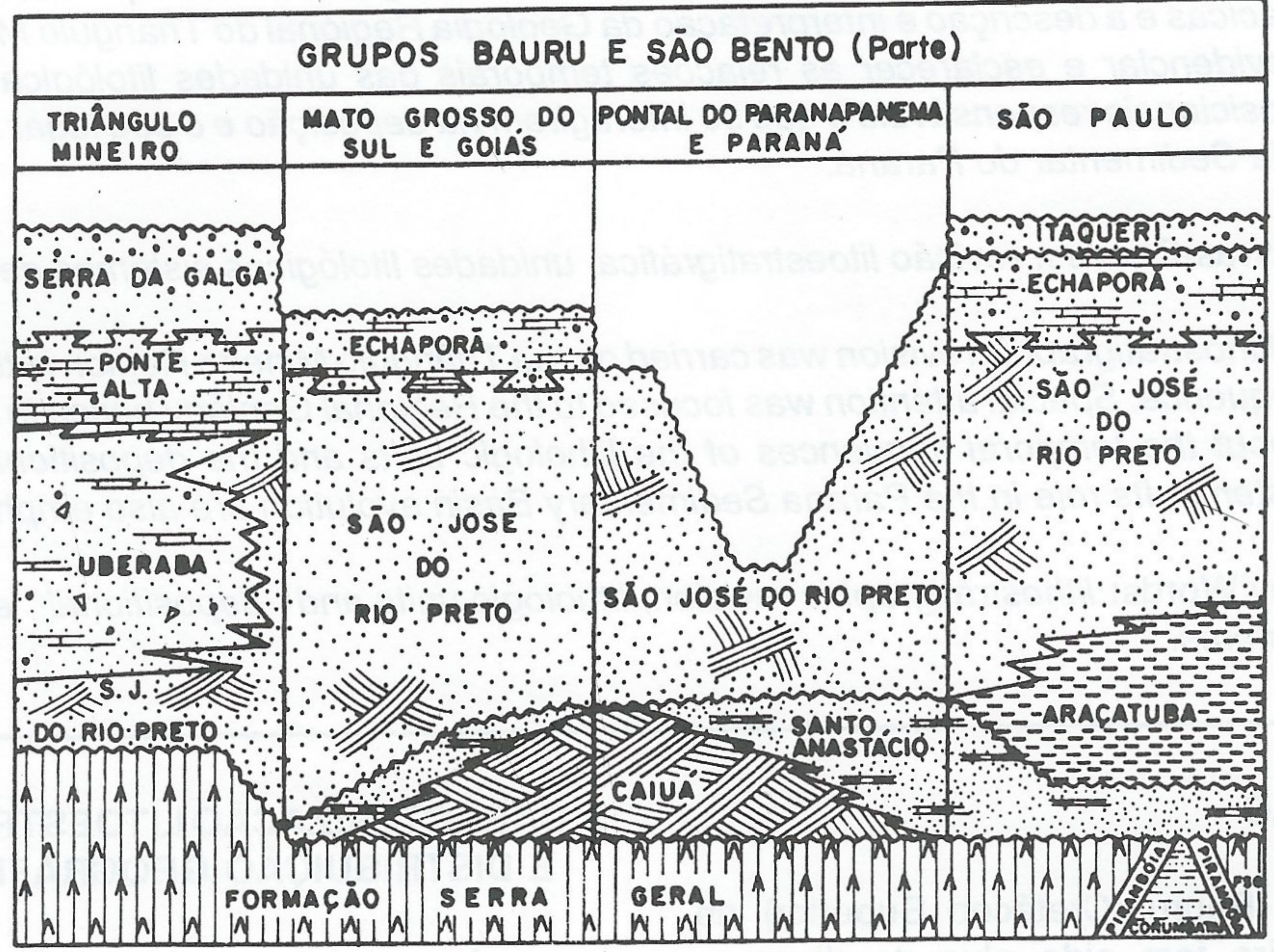

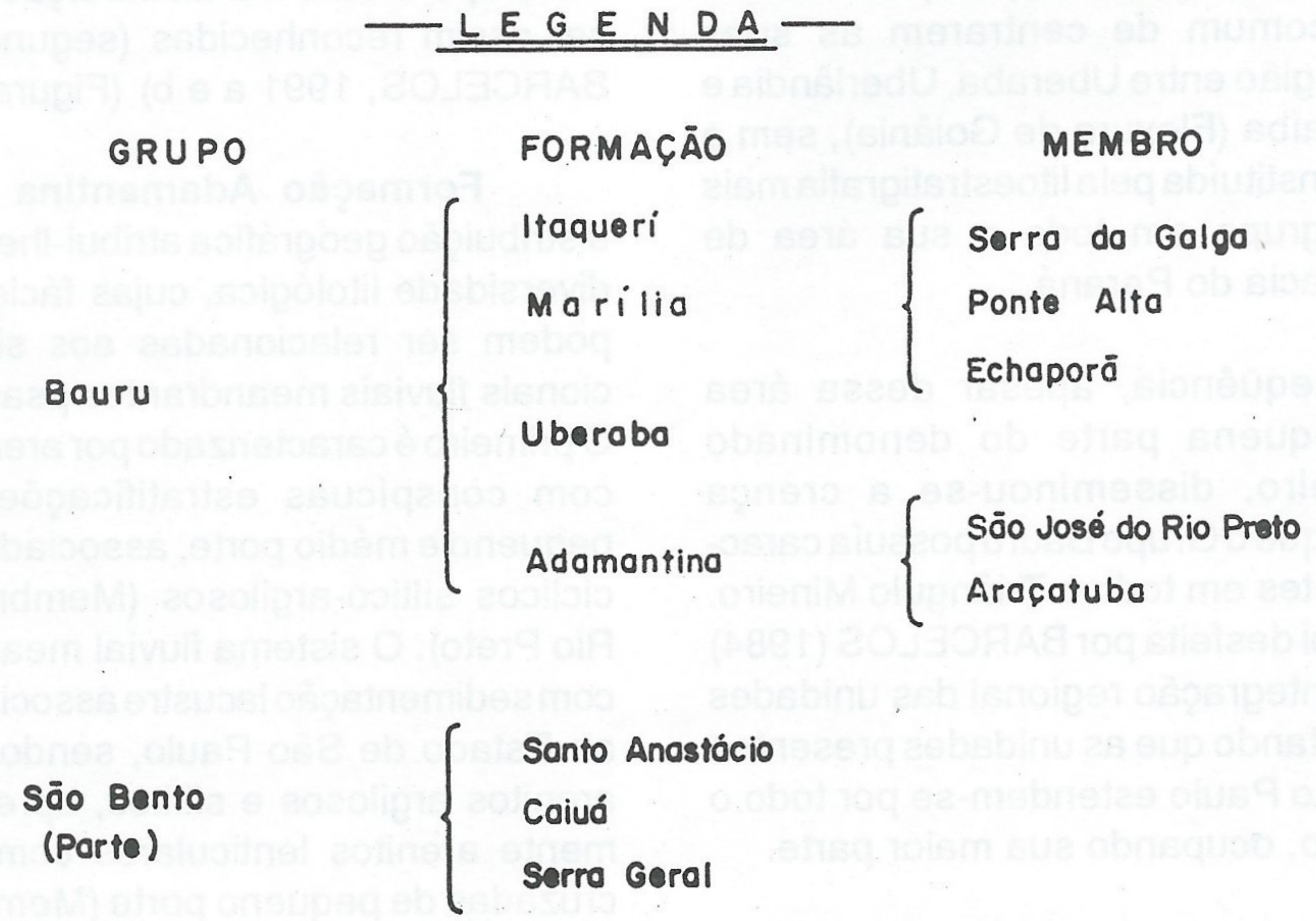

Figura 1: - Distribuição Litoestratigráfica e Geográfica do Grupo Bauru, segundo FULFARO \& BARCELOS, 1991. a bodificado de BARCELOS, 1984). 
Formação Marília - Composta de arenitos grossos e conglomeráticos, localmente apresentando calcretes nodulares e calcários bastante puros. Outras vezes comporta sedimentos conglomeráticos pouco litificados. Os arenitos grossos ocorrem extensivamente no Triângulo Mineiro, sul de Goiás, sudeste de Mato Grosso do Sul, com as mesmas características verificadas no Planalto Echaporā em Marília e Monte Alto, no Estado de São Paulo (Membro Echaporā). Os níveis de calcretes associados a calcários puros, estudados em detalhe por SUGUIO \& BARCELOS (1983), de origem lacrustre, são conhecidos por Membro Ponte Alta. Os arenitos conglomeráticos, friáveis, ricos em estratificaçōes cruzadas, constituem o Membro Serra da Galga. A Formaçāo Marília teria sido depositada em condiçōes de clima semi-árido (SUGUIO \& BARCELOS, 1983), com sistemas de leques aluviais de regime torrencial, caracterizados por arenitos conglomeráticos, calcretes e camadas descontínuas de lamitos avermelhados.

\section{O GRUPO BAURU NO TRIÂNGULO MINEIRO}

\section{1 - Histórico}

A estratigrafia desse grupo, nessa regiāo do Estado de Minas Gerais, apresenta certas peculiaridades não comumente encontradas nas exposições dos sedimentos dessa unidade nos demais estados onde ocorrem. Esses aspectos particulares têm início com a própria Formaçāo Uberaba, unidade basal sobrejacente aos basaltos daFormaçãoSerra Geral e prosseguem na unidade superior, Formação Marília, com os membros Ponte Alta e Serra da Galga. (Figura 2).

O último trabalho de síntese sobre esse grupo nessa regiāo foi efetuado por BARCELOS (1984). Nesse trabalho, além de outros aspectos, esse autor redefine a litoestratigrafia dessa área, propondo os acima mencionados membros Ponte Alta e Serra da Galga para a Formaçāo Marília.

Segundo OLIVEIRA \& LEONARDOS (1943), a Formação Uberaba foi descrita por HUSSAK (1906 a e b), porém a sua denominaçāo, como ela é conhecida atualmente, deve-se a RIMANN (1918 in FREYBERG, 1932).

HASUI (1968 a 1969) apresentou o primeiro mapa geológico de sedimentos cretáceos do
Triângulo Mineiro e parte do Alto Paranaíba (Minas Gerais), onde sugeriu a ausência de indícios de ligação dos arenitos do planalto da Mata da Corda com as Formaçóes Bauru ou Botucatu, através do Corredor do Quebra Anzol (Arco da Canastra). Correlacionou as rochas com contribuiçáo vulcânica de Uberaba com parte dos vulcanitos do planalto da Mata da Corda, agrupando-os sob o nome Formaçāo Uberaba. Admitiu, ainda, a existência de uma disconformidade (discordância paralela) entre a "Formaçāo Bauru" e a Formaçáo Uberaba. A "Formaçāo Bauru" desse autor corresponde aos sedimentos em contato gradacional sobre a Formaçāo Uberaba. Importante trabalho foi desenvolvido por BARBOSA et al. (1970), que admitiram a "Formação Bauru"na área de Uberaba (MG), constituída pelas fácies: Uberaba, Ponte Alta e Bauru, da base para o topo.

A "fácies" Uberaba é essencialmente constituída de sedimentos tufáceos (tufitos e argilitos cineríticos associados a conglomerados), sobrepondo-se discordantemente sobre os basaltos da Formaçāo Serra Geral. BARBOSA et al. (op.cit.) situaram o limite superior pouco abaixo do calcário conglomerático, apresentando uma espessura média de $80 \mathrm{~m}$. A "fácies" Uberaba se distribuiria em duas áreas distintas, na regiāo de Uberaba e na regiāo da Serra da Mata da Corda e com algumas manchas isoladas entre as duas áreas.

A Formaçāo Uberaba foi reconhecida e caracterizada por SUGUIO et al. (1979) e SUGUIO (1980) na margem nordeste da Bacia do Paraná (regiāo de Monte Carmelo e Romaria, MG). BARCELOS et al. (1981) sugeriram que se mantivesse a designaçāo Formação Uberaba,, considerando-a como seqüência basal do Grupo Bauru na área e correlacionável à Formação São José do Rio Preto (SUGUIO, 1980) ou Formaçáo Adamantina (SOARES et al., 1980).

A "fácies" Ponte Alta, representada por um conjunto de arenitos muito carbonáticos e calcários conglomeráticos, estaria situada acima das rochas piroclásticas. Foi abandonada por SAD et al. (1971), que utilizaram a designação "fácies" Itaqueri. HASUI \& SADOWSKI (1972) argumentaram que "Membro" Itaqueri e "fácies" Ponte Alta são dois nomes para unidades perfeitamente correlacionáveis e sugeriram a 


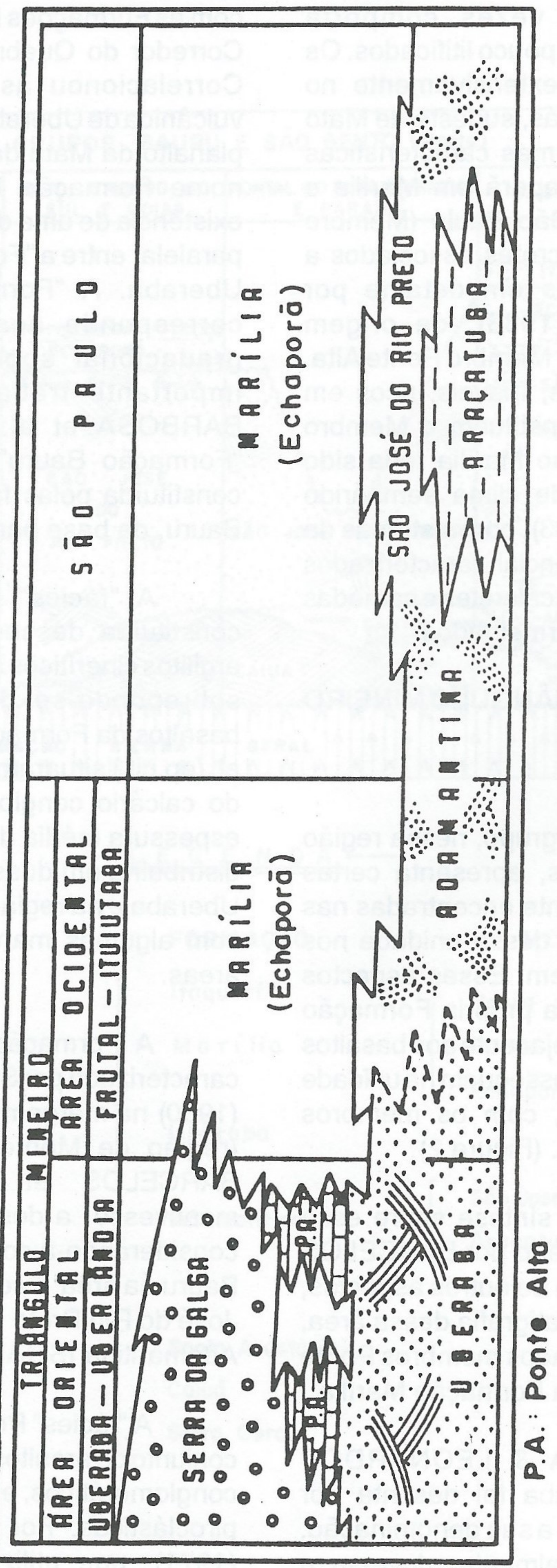

Figura 2: - O GRUPO BAURU NO TRIÂNGULO MINEIRO E NORTE DO ESTADO DE SÃO PAULO. (Seg. FULFARO \& BARCELOS, $1991 \mathrm{~b}$ ). 
utilização "fácies"Itaqueri. SUGUIO (1973) adotou indistintamente os nomes Ponte Alta ou Itaqueri, mas sugeriu que "fácies" Ponte Alta poderia ser melhor definida na área de Ponte Alta (MG). COIMBRA (1976) englobou a "fácies" Ponte Alta na "fácies" C, por ele definida, associando também a essa unidade a "fácies" Calconglomerática (Formação Bauru Superior) de Soares \& Landim (1975). Posteriormente, SUGUIO et al. (1977) e SUGUIO (1980) colocaram esses sedimentos na porção basal da litiofácies Marília, correspondente à fase final da sedimentaçāo Bauru.

\section{2.- Distribuição Regional}

A Formação Uberaba apresenta uma brecha sedimentar ou conglomerado basal onde se destacam fragmentos de basalto, seguidos de arenitos vulcânicos de granulometria média, com proporçōes variáveis de grânulos e pequenos seixos. Ocorrem também siltitos e argilitos de cor vermelha em níveis com espessura centimétrica, predominando os termos mais arenosos para o topo. Saao rochas epiclásticas, segundo classificaçāo de FISCHER (1961), isto é, rochas vulcanoclásticas que mostram detritos oriundos da erosão de rochas vulcânicas pré-existentes misturados com fragmentos de rocha de origem nāo vulcânica.

Foi observado por HASUI (1968) que na parte basal da seqüência predomina o cimento carbonático e no topo ocorre matriz argilosa de coloraçāo verde e ou vermelha.

Os litossolos apresentam estratificação plano-paralela horizontal, laminação cruzada e estratos maciços, com espessura variando entre milímetros e vários decímetros. Forma uma faixa que se estende da regiāo de Veríssimo até Sacramento, passando por Uberaba, Peirópolis e Ponte Alta e para norte sua extensāo nāo é conhecida, porque é recoberta pela Formaçāo Marília (Membro Ponte Alta).

A espessura da Formaçāo Uberaba varia de 85 a $90 \mathrm{~m}$ em Peirópolis, $60 \mathrm{~m}$ na cidade de Uberaba e $27 \mathrm{~m}$ na Serra da Galga. Foi também reconhecida no Alto Paranaíba, na regiāo de Romaria, por SUGUIO et al.(1979). Segundo esses autores, nessa área a Formação Uberaba é constituída por seqüência sedimentar gradacional, apresentando um conglomerado polimítico basal, com matriz argilosa e localmente areno-argilosa, de coloração avermelhada. A espessura desse conglomerado varia entre 4 e $9 \mathrm{~m}$, sendo seu embasamento constituído por arenitos da Formaçāo Botucatu ou micaxistos do Grupo Araxá, sempre em discordância angular. Sobrepöem-seIhes arenitos finos e grossos, com espessura média de 10 a $12 \mathrm{~m}$ e intercalaçóes de níveis conglomeráticos delgados, de coloração esverdeada. Possivelmente essa coloraçāo retrata a contribuiçāo de materiais do vulcanismo alcalino cretáceo do oeste de Minas Gerais (HASUI, 1969).

HASUI (1968) salientou que o contato basal daFormação Uberaba se dá por discordância paralela, com aFormação Serra Geral, englobando fragmentos de basaltos sotopostos. Sob o viaduto da FEPASA, na rodovia BR-050, entre Delta e Uberaba, foi observado esse contato basal formado por brecha sedimentar constituída por arenitos finos e argilosos contendo fragmentos de basalto (BARCELOS, 1984). O contato superior é gradacional com a Formação Marília. Este pode serobservado na rodovia BR-262 nas proximidades de Ponte Alta e na BR-050, entre Uberaba e Uberlândia, após o Rio Uberaba, onde corpos de arenitos grossos esverdeados da Formaçáo Uberaba passam para os calcáreos e conglomerados do Membro Ponte Alta (Formaçāo Marília). Na regiāo de Romaria, no Alto Paranaíba, esses sedimentos assentam-se em discordância angular sobre os arenitos da Formaçāo Botucatu e micaxistos do Grupo Araxá.

A Formação Uberaba interdigita-se com a Formaçāo Adamantina a noroeste da regiāo de Uberlândia, em direção a Ituiutaba e Prata, e em direção a Veríssimo. Nessa área já afloram sedimentos da Formação Adamantina, capeados por sedimentos da Formaçāo Marília, nāo sendo mais encontrados os sedimentos da Formação Uberaba (Figura 3).

Essas zonas de interdigitaçāo distam, em média, uma centena de quilômetros da principal área fonte, o Alto Paranaíba, onde se desenvolveram intensos processos magmáticos associados ao seu soerguimento (HASUI \& HARALYI, 1990). Sāo as rochas provenientes desses processos vulcânicos associados a esse evento que váo constituir de maneira acentuada a sedimentaçāo da Formação Uberaba, fazendo com que seu conteúdo em detritos de origem 


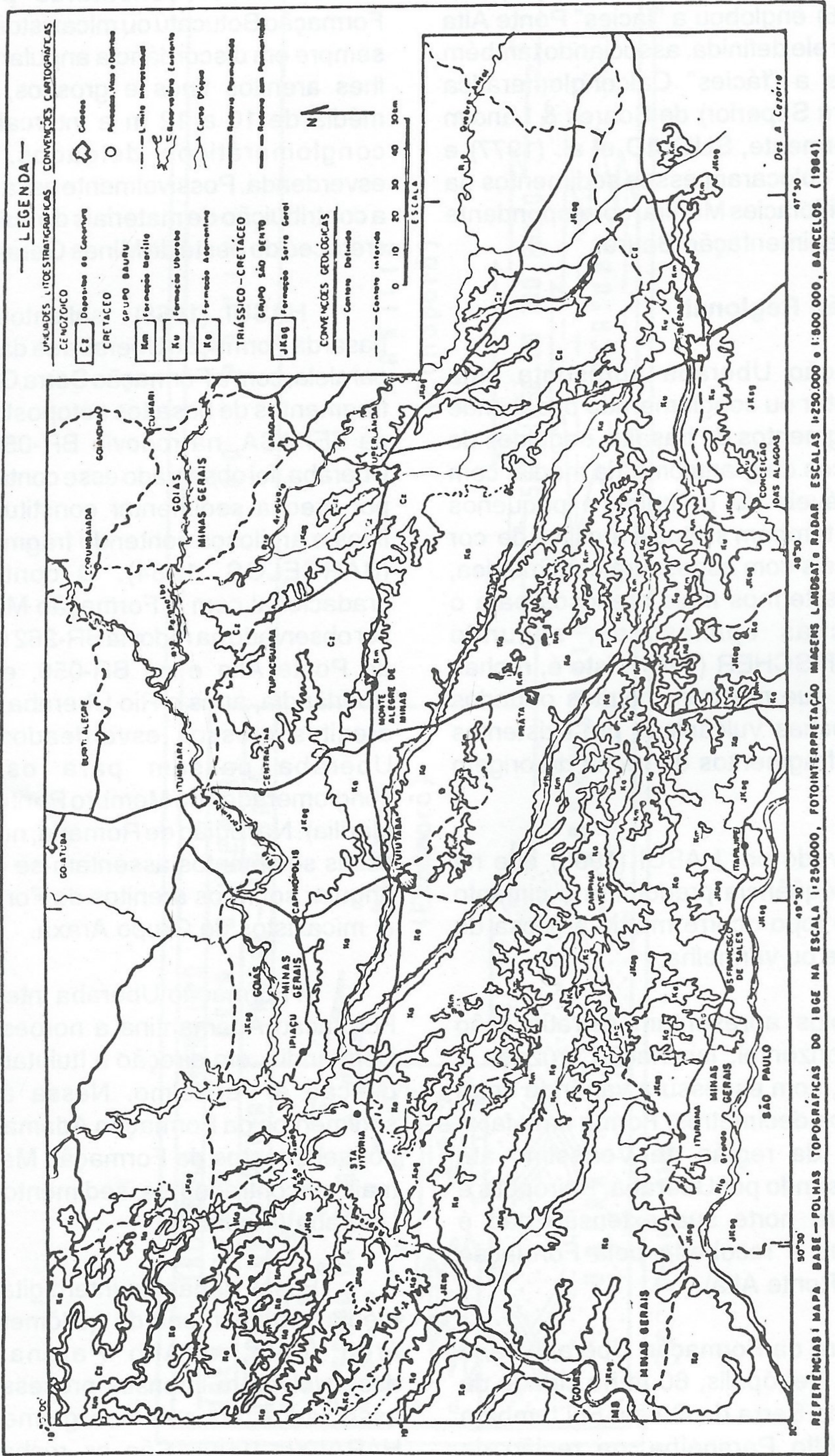

Figura 3: - MAPA GEOLÓGICO DO TRIÂNGULO MINEIRO (MG). 
vulcânica e sua cor esverdeada original a diferenciem da sedimentaçāo sincrona, mais afastada, dos sedimentos denominados Formaçāo Adamantina.

HASUI (1968) interpretou que o ambiente deposicional dessa seqüência teria sido fluvial, mas com pequeno transporte, tendo em vista a presença de detritos semi-decompostos ou decompostos que nāo suportariam as vicissitudes mecânicas de transporte a longa distância, mas mencionou também a presença de detritos vindos de mais longe.

SUGUIO et al. (1979), baseados nos estudos de composiçāo (litologia dos conglomerados e mineralogia das fraçōes pesadas), estruturas sedimentares etc. sugeriram que, na área de Romaria, o transporte e deposiçāo estiveram ligados aos fluxos de detritos e corridas de lama, tendo sido depositados em irregularidades do embasamento na forma de leques aluviais originados em climas secos. De modo geral, SUGUIO (1980) sugeriu que a deposiçāo teria se processado em condiçóes flúvio-lacustres, com forte contribuição de produtos de vulcanismo alcalino.

O ambiente de deposição é fluvial de características meandrantes, sob clima úmido em bacia hidrográfica exorréica com nível de base voltado para SW. A planície São José do Rio Preto/PresidentePrudente é a continuação paulista da Planície Uberaba no Triângulo Mineiro. Um ponto nāo resolvido de maneira plena é sobre o tipo de cobertura vegetal que devia certamente existir nessas planícies. Chama a atenção a ausência de restos vegetais fósseis, nesta e em outras formaçōes do grupo, de árvores de grande porte através da preservação de seus troncos.

Os restos vegetais indicam flora arbustiva predominante. Embora a litologia dessas unidades nāo seja a mais favorável aos processos de fossilização, a presença de restos de répteis, moluscos e peixes fósseis indicam que esse mecanismo existiu. A fauna fóssil, especialmente a reptiliana é, em grande parte, herbívora e a cobertura vegetal dessas planícies deveria prover o alimento necessário. A única evidência de regiāo florestada encontra-se no limite da antiga bacia, próxima ao distrito industrial de Uberlândia, já no vale do Rio Araguari, constituída por troncos fossilizados de Podocarpacceae, descritos erroneamente por SUGUIO \& COIMBRA (1972) como pertencentes à Formação Botucatu de idade Triássica-Jurássica. Um nível de arenitos intertrapianos nos basaltos da Formaçāo Serra Geral (Cretáceo Inferior), próximo ao jazigo, foi a provável causa dessa falso posicionamento estratigráfico.

Delineia-se assim a provável paleogeografia da planície Uberaba/Adamantina, com cobertura florestal ao menos próxima às montanhas da atual regiáo da Serra da Canastra seguindo para W/SW, em gradiente suave, para planícies de rios meândricos do mesmo sistema até regióes lacustres mais centrais, representados pelas litologias aflo-rantes na regiāo de Araçatuba (SP) (fácies Araçatuba de SUGUIO et al., 1977, MembroAraçatuba, de BARCELOS, 1984). Apesar dos lagos mais centrais, é importante assinalar o caráter exorréico dessa drenagem, fluindo de maneira geral rumo sul até a atual regiāo do estuário do Prata. Deve ser lembrado que depósitos cretácicos síncronos, tanto continentais como marinhos, existem em superfície e sub-superfície no Paraguai e Argentina.

O topo da Formaçāo Uberaba, bem exposto no flanco norte do vale do Rio Uberaba na BR-050 (Uberaba-Uberlândia), representa bem as mudanças existentes entre o início de sua deposição e os eventos que se sobreporiam à sua drenagem. O afloramento acima citado já foi descrito por BARCELOS (1989), mas o que é ressaltado aqui é o caráter de afogamento da drenagem meândrica até entāo existente. A arquitetura das camadas indica uma planície de inundação ao nível quase lacustre, inclusive com pequenas indicaçóes de fluidização nas lentes arenosas. O caráter exorréico da bacia é visivelmente constrangido por um mecanismo de barramento, melhor expresso no Triângulo Mineiro, devido à proximidade das terras altas marginais $\mathrm{e}$ conseqüente maior continuidade do sistema de drenagem. Em outras áreas da bacia de sedimentaçāo a passagem desse sistema para o superior é brusca e provavelmente seguida de um hiato.

A idade dessa formaçāo deve também ser interpretada com base nas relaçóes de contato com as unidades estratigráficas próximas e no seu conteúdo fossilífero. Ocorre contato 
interdigitado com a Formação Adamantina, gradacional $e$, às vezes, interdigitado com a Formaçāo Marília. Essas relaçōes estratigráficas permitem atribuir uma idade provável semelhante à atribuída para a Formação Adamantina, isto é, Senoniana. Quanto ao conteúdo fossilífero, apesar de ser pobre, é representado por fragmentos ósseos provavelmente de répteis, semelhantes aos encontrados na base da Formação Adamantina.

As ocorrências da Formação Marília são representadas por consideráveis espessuras de arenitos imaturos e conglomerados superpostos a níveis carbonáticos.

Esses sedimentos sāo, em geral, caracterizados por grande heterogeneidade, com manchas de formas e cores variadas, aspectos nodulares e/ou brechóides. Porém, em alguns casos, foram encontrados também calcários micríticos de textura mais homogênea (SUGUIO E BARCELOS, 1983).

Aos calcáreos associam-se, lateral e verticalmente, calcretes. Esses calcretes foram estudados por SUGUIO \& BARCELOS (1983) e constituem-se em materiais de origem continental, onde o carbonato de cálcio ocorre no estado pulverulento ou nodular, provocando a cimentação em maior ou menor quantidade de solo ou rocha, primariamente na zona vadosa. O reconhecimento de calcretes em seqüências sedimentares antigas, como é o caso dessa formação, é de fundamental importância na reconstruçăo paleoambiental por duas razōes. Em primeiro lugar, os calcretes ocorrem nos dias atuais extensivamente distribuídos em regiōes quentes e semi-áridas, sendo portanto indicadores paleoclimáticos. Em segundo lugar, eles parecem evidenciar sedimentaçāo subaérea, embora alguns admitam origem estromatolítica em condiçōes lacustres, lagunares ou mesmo marinhas. Esses depósitos de calcretes, pertencentes à Formação Marília, que se acham muito bem desenvolvidos no Triângulo Mineiro, distribuem-se também pelos Estados de São Paulo, sul de Goiás e Mato Grosso do Sul.

Na regiāo de Uberaba (MG) os calcretes podem ser descritos como um calcáreo de cores rosa-alaranjada moderada a cinza-amarelada, sem estratificaçōes, contendo muitas vezes impurezas arenosas de quartzo e seixos bem arredondados de quartzo, quartzito e sílex. São comuns as feiçōes nodulares e manchas parcialmente arenosas conferindo-lhes coloraçāo mosqueada. Comumente apresentam-se como corpos lenticulares de extensăo restrita, mas onde o seu desenvolvimento é maior associam-se-lhes calcáreos muito puros de provável origem lacrustre, como acontece em Ponte Alta (MG) e no Km 45 da BR-050 (Uberaba-Uberlândia), onde eles sāo explorados para fabricaçāo de cimento.

Os termos litológicos principais do Membro Serra da Galga apresentam-se em torno de onze classes texturais e compóem-se de arenitos conglomeráticos, conglomerados arenosos, conglomerados e arenitos, variando desde conglomerado com matriz arenosa até argilito síltico-arenoso demonstrando, segundo os critérios de FOLK (1951), baixa maturidade e seleção pobre. Nesses conglomerados predominam seixos de quartzitos, seguidos de quartzo, sílex (calcedônia), magmatito básico, calcário e argilito, cujos diâmetros maiores situam-se entre 1,5 até quase $10,0 \mathrm{~cm}$, tendo o embasamento cristalino (Grupos Araxá e Canastra) como fonte principal.

No trabalho de BARCELOS et al. (1981) foi mostrado também que as passagens entre as camadas sāo transacionais ou bruscas. Quando uma camada mais grosseira passa rumo ao topo para termos mais finos a passagem é, em geral, gradual, mas quando sobre termos finos sobrepóem-se camadas de materiais grosseiros, a passagem é geralmente erosiva, definida por estruturas de escavação e preenchimento. Normalmente, dentro dos bancos mais espessos, em sedimentos arenosos ou conglomeráticos, pode-se notar uma inciiente gradação de granulometria, com termos texturais cada vez mais finos rumo ao topo, sendo interrrompidos pelo início de nova seqüência grossa. Em geral essa gradação não é muito nítida, com exceção dos casos em que na parte basal da seqüência se fazem presentes termos conglomeráticos. Os termos conglomeráticos, além de serem constituídos de seixos de quartzo e quartzito, apresentam também bolas e pelotas de argila. $O$ contato superior de passagem de termos conglomeráticos e/ou arenosos para materiais mais finos é, em geral, transacional, mas o contato superior de camadas argilosas e sílticas com material mais grosseiro é comumente brusco. 
$\mathrm{Na}$ base do Membro Serra do Galga os sedimentos apresentam cimento carbonático preenchendo os espaços entre os grãos de quartzo e a matriz argilosa e, na regiāo de Ponte Alta, ocorrem fragmentos de calcário do tamanho de seixos incluídos em camadas arenosas sobrepostas a leitos calcáreos.

Interessante também nesse membro e nos leitos de calcário do Membro Ponte Alta é a presença do argilo-mineral do grupo atapulgita. Ocorre disseminado nos sedimentos ou formando material placóide de cor esbranquiçada. Essas placas acham-se intercaladas dentro de seqüências areno-argilosas, com espessuras de 3 a $5 \mathrm{~cm}$ e estendendo-se lateralmente por vários metros. Esse argilo-mineral foi descrito por SUGUIO (1973) e SUGUIO \& BARCELOS (1978) e SUGUIO et al. (1980). Além de sua importância econômica, conforme salientaram aqueles autores, apresenta também importante significado geológico, corroborando a hipótese de existência de clima árido durante a deposição dos sedimentos do Grupo Bauru.

Os sedimentos do Membro Serra da Galga constituem uma cobertura de topos aplainados e orlas escarpadas e estão insulados pelos rios Grande, Paranaíba e Araguari (SUGUIO, 1973; BARCELOS et al., 1981 e BARCELOS, 1984).

As ocorrências de calcáreo do Membro Ponte Alta estendem-se desde cerca de $15 \mathrm{Km}$ ao norte de Sacramento até Frutal, passando por Uberaba. Essa faixa de afloramento margeia a borda escarpada de uma feiçāo geográfica denominada chapadão, cujo topo chega a ser superior a $1.000 \mathrm{~m}$ de altitude e possui suave declividade para sudoeste, estendendo-se a leste rumo a Araxá, a oeste para Frutal e a norte para Uberlândia. Em direção a Iturama, Campina Verde, Ituiutaba e Santa Vitória passam a constituir e sustentar os grandes chapadóes divisores de água dos principais rios da regiāo, constituindo os depósitos do Membro Echaporā. Esses sedimentos ocorrem a partir da cota de 500-520 m até $760 \mathrm{~m}$ de altitude, nessas áreas. Elevaçóes menores, entre 60 a $100 \mathrm{~m}$ de altura formam os interflúvios dos rios de menor porte, e constituem ramificaçōes secundárias daqueles chapadóes de maior porte.

Normalmente os depósitos sedimentares formam bancos com 4 a $5 \mathrm{~m}$ até mais de $10 \mathrm{~m}$ de espessura de calcário arenoso e calcário arenoso conglomerático, às vezes formando até brechas calco-arenosas intercaladas em sedimentos finos a grossos até conglomeráticos. Normalmente esses termos litológicos estāo capeados por sedimentos areno-conglomeráticos do Membro Serra da Galga. Interessante é a tendência desses calcáreos de se tornarem mais arenosos à medida que se distanciam da Flexura de Goiânia, em direção ao oeste do Triângulo Mineiro. Provavelmente esse fato esteja relacionado com a distância da área fonte fornecedora de carbonato de cálcio, representada pelo Grupo Bambuí e passam a constituir os depósitos sedimentares do Membro Echaporā.

A espesssura do Membro Serra da Galga foi calculada por SUGUIO (1973) em torno de 100 m, mas HASUI acredita que na Serra de Ponte Alta, continuação para leste da Serra da Galga, seria da ordem de $220 \mathrm{~m}$. Nas serras das regiōes de Prata e Campina Verde o Membro Echaporã apresenta espessuras de mais de $250 \mathrm{~m}$.

Os calcáreos constituem camadas com espessuras variáveis, tendo o conglomerado basal ("casco de burro"- designação popular), espessura de 10 a $20 \mathrm{~m}$. Na Serra das Paineiras (Uberaba, $M G)$ esse conglomerado perde o seu caráter basal, sobrepondo-se a arenitos carbonáticos, os quais assentam-se sobre arenitos turfáceos da Formação Uberaba. Essa mesma situação estratigráfica foi verificada rumo a oeste do Triângulo Mineiro, diferenciando-se, no entanto, pelo fato de esses conglomerados nāo estarem sobrepondo os sedimentos da Formação Uberaba, mas sim os da Formaçāo Adamantina.

Os calcáreos mais homogêneos ocorrem comumente em forma de corpos lenticulares de cerca de $1 \mathrm{~m}$ de espessura com extensāo de alguns metros, envoltos por arenito argiloso carbonático. Na regiāo de Ponte Alta as camadas são mais possantes e sondagens têm demonstrado a existência de maior continuidade apresentando, segundo BARBOSA etal. (1970), área cartografada superior a $120 \mathrm{Km}^{2}$.

No Triângulo Mineiro os sedimentos da Formação Marilia repousam em contato gradacional e, às vezes, interdigitado com a Formação Uberaba, entre as localidades de Veríssimo, Peirópolis e Uberaba. Nas imediaçōes 
de Prata, Campina Verde, Monte Alegre de Minas, em direçāo a Goiás e Mato Grosso do Sul, está em contato também gradacional e/ou interdigitado com a Formação Adamantina (Figura 3).

O contato entre os Membros Ponte Alta, Serra da Galga e Echaporā apresenta-se ora gradacional, ora abrupto, apresentando conglomerado basal mais desenvolvido e associado às camadas de calcário, ocorrendo também passagem lateral de conglomerado para calcários arenosos impuros com seixos de vários tamanhos.

Interessantes relaçōes de contato entre esses membros foram observadas em fundo de bossoroca (SUGUIO, 1973), onde se verificam lenticularidades das camadas de topo dos calcários. A seqüência apresenta $7,76 \mathrm{~m}$ de arenito muito argiloso, maciço, com seixos esparsos e placas de atapulgita, capeado por $1,10 \mathrm{~m}$ de argilito síltico, tendo na base arenito fino carbonático e possuindo lentes de calcários intercaladas, com 2 a $3 \mathrm{~m}$ de comprimento.

Em seção exposta pela exploraçāo de calcários em Ponte Alta foi verificado contato abrupto, onde um pacote constituído de alternância de leitos de conglomerado, arenito argiloso e sílex que se assentam sobre banco de calcário localmente conglomerático.

A Formaçāo Marília apresenta um comportamento transgressivo em relação à Formaçāo Adamantina, ultrapassando os limites geográficos desta, sobrepondo-se diretamente aos basaltos da Formação Serra Geral e também recobrindo paleoaltos existentes na Bacia Bauru (Figura 3).

Seus depósitos desenvolveram-se em regimes torrenciais característicos de leques aluviais, de clima semi-árido, provenientes de arcos marginais.

No Triângulo Mineiro as atividades tectônicas nessas faixas marginais recrudesceram durante o levantamento do Arco da Canastra, propiciando o desenvolvimento de depósitos de movimentos de massa.

A deposição dos sedimentos do Membro Serra da Galga ocorreu sob condiçōes de alto declive, desenvolvendo leques aluviais caracterizados por regimes torrenciais e canais anastomosados em regióes próximas a arcos marginais, supridos por elevada carga sedimentar, conforme se pode deduzir das geometrias dos litossomas e das propriedades texturais de seus sedimentos.

As estruturas sedimentares presentes nesses depósitos são predominantemente as estratificaçōes plano-paralelas, estratificaçōes cruzadas, estrutura maciça e estratificaçāo gradacional. As estratificaçōes plano-paralelas, na realidade, não chegam a constituir planos perfeitamente horizontais em funçāo da lenticularidade dos litossomas, principalmente nas litologias mais grosseiras. Essas laminaçōes foram observadas com muitafreqüência em alguns níveis de seção-tipo e na seção-de-referência do Membro Serra da Galga, onde arenitos finos e argilosos conglomeráticos se intercalam (segundo BARCELOS, 1984).

A estratificação cruzada (acanalada e/ou tabular) mostra-se bem conspícua em diversos níveis nos afloramentos observados. Esses níveis apresentam forma lenticular e são constituídos de arenito conglomerático e os seixos acompanham as camadas frontais das estratificaçóes cruzadas. As estratificaçōes cruzadas tabulares apresentamse com camadas frontais de 5 a $6 \mathrm{~m}$ de comprimento e ns planos dessas camadas aparecem pelotas de argila (menos de $1 \mathrm{~cm}$ ) e algumas bolas de argila (mais de $10 \mathrm{~cm}$ ).

Nos níveis de granulação mais fina intercaladas entre as lentes conglomeráticas e arenosas ocorrem estratificaçōes menores do tipo acanalado, com camadas frontais de 20 a $30 \mathrm{~cm}$ de comprimento.

Estrutura maciça parece ser uma feição bem característica do Membro Serra da Galga, sendo reconhecida dentro de bancos de arenitos e raramente nos argilitos. A estrutura maciça aparece indistintamente dentro dos corpos de arenitos, siltitos e argilitos, e também nos bancos de calcários arenosos do Membro Ponte Alta.

Os dois membros, Serra da Galga e Ponte Alta, tornaram-se inadvertidamente os representantes da litologia da Formação Marília em toda a regiāo do Triângulo Mineiro. Como já 
mencionado, suas distribuiçōes estāo, também, associadas a processos marginais deste limite da antiga bacia. Entre esses dois membros e o evento anterior, Formação Uberaba, há, nas características dos sedimentos preservados, uma dramática mudança climática.

A passagem da unidade subjacente para os membros Ponte Alta e Serra da Galga é, em muitos lugares, brusca e, devido às litologias, causa um acentuado destaque no relevo uma vez que, por erosāo diferencial, os membros superiores formam serras por toda a regiāo de sua ocorrência. Há que destacar, no entanto, que existem indícios de um afogamento no topo da Formação Uberaba, sinalizando o fato mais importante dessa passagem, que é representado pela mudança do caráter exorreico anterior para o endorreismo pronunciado que baliza a sedimentaçăo da Formaçāo Marília (Figura 4).

O endorreismo que passa a vigir nessa época é fruto de reflexo continental devido a movimentaçōes de idade Turoniano ao final do Campaniano na margem continental Atlântica. As terras altas do Alto do Paranaíba servem de área fonte para a sedimentação do leste do Triângulo Mineiro, contribuindo inclusive com a cobertura carbonática do Grupo Bambuí (Proterozóico Superior) para a intensa sedimentaçāo dos calcáreos do Membro Ponte Alta, como já apontado por BARCELOS (1984).

Os calcários do Membro Ponte Alta, já descritos por SUGUIO (1973) e SUGUIO \& BARCELOS (1983) sāo provenientes de sedimentação lacustre e estão interdigitados com - Membro Serra da Galga e, como verificado neste trabalho, com sedimentos da Formação Marília propriamente dita, ou Membro Echaporã de BARCELOS (1984). Essa interdigitação com a faciologia Echaporã, anteriormente não apontada, introduz um novo conceito na gênese desses calcários. Sua origem é lacustre e está associada a barramentos naturais ligados ao próprio processo de transporte dos leques aluviais (Membro Serra da Galga). Encontram-se no interior dos corpos calcários brechas e conglomerados similares aos do Membro Serra da Galga, em forma de blocos que representam pontos terminais de deslizes subaquáticos dessa faciologia marginal para o interior dos lagos.
A camada calcária (o teor de $\mathrm{MgO}$ desses calcários é muito baixo) não é contínua em toda a regiāo leste do Triângulo Mineiro como suposto anteriormente. São lenticulares e pelo menos duas lentes existem que permitem exploraçāo econômica. Uma na regiāo homônima de Ponte Alta, a $30 \mathrm{Km}$ de Uberaba, na estrada entre essa cidade e Araxá, jazida de uma indústria de cimento, e outra na BR-050 (Uberaba-Uberlândia), no Km 45. Separando-as encontra-se a faciologia do Membro Echaporā diretamente acima da Formação Uberaba, como exposto na rodovia Uberaba/Ponte Nova. Em toda a regiāo percorrida nāo foi encontrada mais nenhuma ocorrência desse porte. São, portanto, dois grandes lagos. Os sedimentos do Membro Serra da Galga representam a parte proximal dos leques aluviais provenientes do NE, que buscam uma faixa de aproximadamente $100 \mathrm{Km}$ do alto marginal. A esses flangomerados seguem-se os depósitos fluviais de rios anastomosados, em faixa paralela, com depósitos de barras longitudinais conglomeráticas, com estratificaçōes cruzadas, aflorantes entre Campo Florido e a Serra do Marimbondo, entre Frutal ePrata. A faixa seguinte nessa distribuição, a partir dos leques proximais, é a zona de "playa lake" propriamente dita, onde se passa a encontrar os detritos ali levados em épocas de pluviosidde mais intensa e ali decantados. E um depósito sem o menor trabalho de agentes geológicos, constituindo verdadeiros solos em que se desenvolviam os processos de formaçāo de calcrete e vegetaçāo, denotada pelos moldes de raízes preservadas. É uma sucessāo monótona de horizontes mais lamíticos com restos de tubos, raízes e fragmentos de crostas de calcrete, nāo raro orientadas em níveis planoparalelos, demonstrando algum retrabalhamento, com camadas mais arenosas com nódulos carbonáticos que caracterizam o membro Echaporā. Estaúltima faixa de ocorrência estendese por todo o oeste do Triângulo Mineiro, até o Rio Paranaíba, adentrando o Estado de Goiás a oeste (Figura 3).

Em um dado plano temporal essas zonas de ocorrência distribuiram-se como arcos simétricos a partir dos altos marginais. Os diferentes pulsos tectônicos causam a interdigitaçāo desses membros. A diminuiçāo progressiva da intensidade de movimentação na área fonte faz com que todo o sistema recue e a faciologia do Membro Echaporā acaba por se

Sociedade \& Natureza, Uberlândia, 5 (9 e 10): 9-24, janeiro/dezembro 1993 


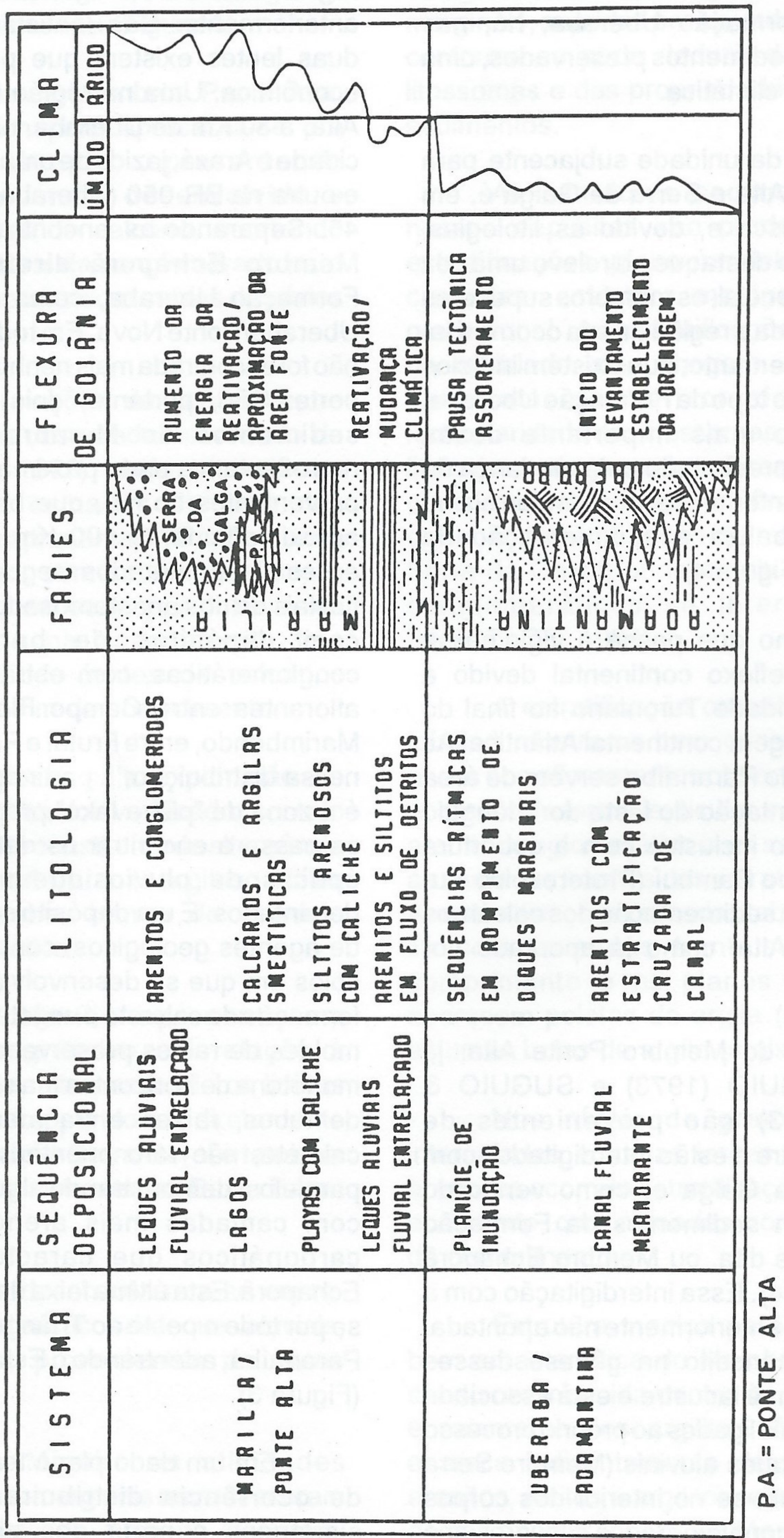

Figura 4: - UNIDADES GENÉTICAS E CONDICIONAMENTO TECTONO - SEDIMENTAR. (Seg. FULFARO \& BARCELOS, 1991 b). 
aproximar do Alto do Paranaíba, recobrindo todos os depósitos anteriores. Desta maneira, não existe uma sucessāo litoestratigráfica tipo "layer cake" entre os três membros apontados para a Formaçāo Marília, mas sim uma interdigitação total entre as três faciologias, desde a base até o topo (Figuras 2 e 4).

O aspecto de um clima árido e semi-árido apontado pela litologia presente nesse sistema Marília/Ponte Alta merece uma discussāo adicional. $O$ endorreismo da bacia é causado por tectonismo, como é comum, inclusive, em processos similares atuais em que o tectonismo está presente. Em tal tipo de bacia a evaporação sempre será maior que a precipitaçāo, agravando a maquiagem climática dos sedimentos ali depositados. O mecanismo de deposição não pode ser o de um sistema fluvial padrāo, por causa da ausência de um nível de base exorreica. Não resta outra alternativa senáo a dos leques aluviais. No entanto, a presença de depósitos provenientes de rios anastomosados indica uma razoável permanência de água. $O$ ponto a que se quer chegar nesta discussão é que nem sempre a indicação climática de uma pilha sedimentar deve ser aceita sem discussão, especialmente no caso de bacias endorreicas, que provocam um agravamento sensível da definição do tipo de clima. As indicaçōes da Bacia Bauru salientam condiçōes semi-áridas no interior da bacia, mas esse clima não pode ser generalizado para todo o continente.

O conteúdo fossilífero das partes inferiores dessa formaçāo é similar à associação faunística da Formação Adamantina, sendo representado por restos encontrados em Colina e Sāo Carlos (peixes, crocodilídeos, saurópoda e theropoda, quelônios e ostracódeos), restos de dinossauros em Taquaritinga e Fernando Prestes (segundo MEZZALIRA, 1974) e dinossauros, quelônios e crocodilídeos, encontrados por PRICE (1950 a e b, 1953 e 1955) no Triângulo Mineiro. Em função desses fósseis foi atribuída idade senoniana. SUGUIO (1980) preferiu siuá-lo no Cretáceo Superior, sem entrar em maiores detalhes cronológicos. SOARES (1981), baseando-se nesse conteúdo fossilífero, atribui-lhe idade entre - Santoniano e Maastrichtiano. ALMEIDA \& MELO (1981) interpretaram a idade dessa formaçāo com base nas relaçóes de contato erosivo com as camadas basais da Formaçāo Adamantina e o contato interdigitado com as camadas superiores, sugerindo assim deposição no final do Senoniano.

\section{EVOLUÇÃO TECTONO-SEDIMENTAR}

Segundo HASUI et al. (1975), a faixa divisória entre as bacias do Paraná e Sanfranciscana, no sul de Goiás e Oeste de Minas Gerais, esteve ativa em pelo menos dois episódios no decorrer do Fanerozóico. O evento mais importante aconteceu durante o Mezozóico quando, entre o fim do Jurássico e o Cretáceo, aquelas regiōes adquiriram notável dinamismo vinculado aos processos de sedimentação e magmatismo alcalino relacionados com a reativaçāo Wealdeniana. Ainda, de acordo com esses autores, em conexão a esses processos, a Flexura de Goiânia retomou sua atividade no sul de Goiás e a oeste de Minas Gerais, tendo nessa área causado intensa movimentação de blocos ao longo de falhas pré-existentes, impondo um contorno direcional NNW à Bacia do Paraná, desenvolvendo o Soerguimento do Alto do Paranaíba.

Durante esses processos implantou-se a depressāo de Uberaba, constituindo bacia restrita que recebeu sedimentos vulcanoclásticosepiclásticos em condiçōes subaquosas, cujo transporte foi de leste para oeste, limitados pela Flexura de Goiânia e alinhamento de Araxá-Rio Grande. A melhoria de seleção granulométrica dos sedimentos para oeste, a partir de conglomerado polimítico pobremente selecionado e brechas, da regiāo de Romaria e Sacramento, para arenitos finos de Veríssimo, é sugestiva dessas paleocorrentes deposicionais. Em uma seçāo vertical, termos arenosos recobrindo sedimentos conglomeráticos podem ser interpretados como indicativos de diminuiçāo de energia de transporte de sedimentos. Os depósitos rudáceos podem estar relacionados a leques aluviais sedimentados próximos a arcos marginais e os depósitos finos representariam as fácies distais desses leques, depositados em condiçōes subaquáticas, por uma drenagem tipo anastomosada. Assim considerada, essa seqüência de arenitos tufáceos associados a raros níveis conglomeráticos, superpostas aos basaltos (região de Uberaba) ou às rochas cristalinas précambrianas (regiāo de Serra da Mata da Corda), foi depositada por sistema fluvial meandrante com ampla contribuiçāo de materiais vulcânicos. Mas 
na margem nordeste da bacia (Alto Paranaíba, $M G)$ seus sedimentos foram transportados por fluxos viscosos de detritos e corridas de lama e depositados nas irregularidades do embasamento, em forma de leques aluviais, segundo SUGUIO et al. (1979).

As atividades tectônicas nessas faixas marginais recrudesceram durante o levantamento do Arco da Canastra, permitindo o desenvolvimento de fluxos de detritos em área delimitada ao sul pelo alinhamento Araxá-Rio Grande. Depósitos de leques aluviais tiveram seus sedimentos parcialmente retrabalhados por rios efêmeros de alta competência. Esse sistema fluvial tipo anastomosado foi responsável pelos depósitos de conglomerados arenosos e carbonáticos, que constituem o Membro Serra da Galga da Formaçāo Marília.

As condições climáticas iniciais desse ciclo eram semi-áridas e áridas, evidenciadas pela abundância de calcretes do tipo paleossolo calcificado, nodular e camada compacta ("hardpan"), associados a calários lacrustres, que constituem o Membro Ponte Alta dessa formação. Relaciona-se a esses fatos a presença de minerais de argila dos grupos da atapulgita e sepiolita (SUGUIO, 1973; SUGUIO etal., 1975; SUGUIO \& BARCELOS, 1978 e SUGUIO et al., 1980).

O clima no fim da deposição do Grupo Bauru nessa regiāo, embora ainda do tipo semiárido, foi um pouco mais úmido que da fase anterior, responsável pela formação dos calcários do Membro Ponte Alta, ensejando a organizaçāo de um sistema fluvial com drenagem tipo anastomosado, submetido a regimes temporários e torrenciais, com retrabalhamento e sedimentos de leques aluviais constituindo os depósitos arenoconglomeráticos do Membro Serra da Galga.

\section{CONCLUSÕES}

Existem, no Triângulo Mineiro, dois sistemas aqui denominados Uberaba/Adamantina e Marília/Ponte Alta (Figura 4). Divergem quanto ao caráter de suas drenagens, exorréico no primeirn e endorréico no segundo. O estabelecimento desses episódios de sedimentaçāo estão ligados aos eventos tectônicos do Mezozóico Superior do Alto Paranaíba ou Flexura de Goiânia.
As litologias das unidades pertencentes aos dois sistemas refletem especificamente condiçōes existentes nas rochas da área fonte $e$ algumas peculiaridades do seu sítio deposicional. A interdigitação é a norma entre as várias faciologias descritas para o Grupo Bauru e a própria interdigitação serve como base para o esclarecimento da gênese e evolução desses sedimentos.

A revisāo litoestratigráfica aqui apresentada não visou a nomenclatura estratigráfica existente, mas o esclarecimento de suas contemporaneidades, sistemas deposicionais que interagiram na deposiçāo e seu lugar na evoluçāo da bacia.

\section{REFERÊNCIAS BIBLIOGRÁFICAS}

ALMEIDA, F.F.M. de \& MELO, M.S. - 1981 - A Bacia do Paraná e o vulcanismo mezozóico. In: Mapa Geológico do Estado de São Paulo, São Paulo, IPT, no 1184 p.46-82.

BARBOSA, O.; BRAUN, O.P.G.; DYER, R.C.; CUNHA, C.A.B.R. da Geologia da regiāo do Triângulo Mineiro. Rio de Janeiro, D.N.P.M., Bol. 136, 1970.

BARCELOS, J.H. Reconstruçāo paleográfica da sedimentação do Grupo Bauru baseada na sua redefiniçāo estratigráfica parcial em território paulista e no estudo preliminar fora do Estado de São Paulo, Rio Claro, IGCE-UNESP/ Campus de Rio Claro, 1984 (Tese de LivreDocência), 190 p., 4 anexos.

BARCELOS, J. H. Influência do Soerguimento do Alto Paranaíba na sedimentaçāo pós-basáltica na área do Triângulo Mineiro (MG), borda NNE da Bacia Sedimentar do Paraná, Geociências, São Paulo, (8):37-54, 1989.

BARCELOS, J.H.; LANDIM, P.M.B; SUGUIO, K. Análise estratigráfica das seqüências cretácicas do Triângulo Mineiro (MG) e suas correlaçōes com as do Estado de São Paulo. In: Simpósio Regional de Geologia 3. Curitiba, 1981. Atas... Curitiba, SBG, 1981, v.2:90-102.

COIMBRA, A.M. Arenitos da Formaçāo Bauru: estudo de áreas fonte. São Paulo, Instituto de 
Geociências-USP, 2v., 1976,(Dissertação de Mestrado).

FOLK, R.L. Stages of textural maturity in sedimentary rocks. J.Sed.Petrol. (21):127-130, 1951.

FREYBERG, B.VON - 1932 - Erbnesse geologischer Forschungem in Minas Gerais (Brasilien) - Neus Jb.Min.Paleon., II, 401 pp. Tradução de J.M. Campos para Simpósio das Formaçōes Eopaleozóicas do Brasil, XIX Congresso Brasileiro de Geologia (1965). Rio de Janeiro.

FULFARO, V.J. \& BARCELOS, J.H. Fase rift na Bacia do Paraná: A Formaçāo Caiuá. In: Simpósio Nacional de Estudos Tectônicos, 3. Rio Claro, Boletim de Resumos... Rio Claro, UNESP/SBG,: 1991a, p.85-87..

FULFARO, V.J. \& BARCELOS, J.H. Grupo Bauru no Triângulo Mineiro: Uma nova visăo litoestratigráfica. In: Simpósio do Sudeste, 2. São Paulo, 1991, Atas... São Paulo, SBG:5966., 1991b, p. 59-66.

HASUI, Y. A Formaçāo Uberaba. In: XXII Congresso Brasileiro de Geologia, Belo Horizonte, SBG, 1968, p. 167 - 179.

HASUI, Y. O Cretáceo do oeste mineiro. Boletim da Sociedade Brasileira de Geologia. São Paulo, 18(1):39-56, 1969.

HASUI, Y. \& HARALYI, N.L.E. O Soerguimento do Alto Paranaíba. In: Simpósio sobre as Bacias Cretáceas Brasileiras. Resumos, Rio Claro, UNESP, 1990, p. 24.

HASUI, Y. \& SANDOWSKI, G.R. Membro Itaqueri e Fácies Ponte Alta. In: XXIV Reuniāo da SBPC, São Paulo. Resumo das Comunicaçōes, São Paulo, SBPC, 24(6):138, 1972.

HASUI, Y.; SANDOWSKI, G.R.; SUGUIO, K. FUCK, G.F. The Planerozoic Tectonic Evolution of the western Minas Gerais State. An.Acad.Bras.Ciênc.,Rio de Janeiro, Acad. Brasileira de Ciências, 47(3/4):431-438,1975.

HUSSAK, E. Uber die diamantilager in Western des Staats Minas Gerais und der anganzernden Staats Sāo Paulo und Goyas, Brasilien.
Zeitscherift fr Prakitisches Geologie, J.g, 14: 318 - 333. 1906a.

HUSSAK, E. A mina de diamante de Água Suja. Zeits.f.pratik.Geol., Jg. 16, 1906 b.

MEZZALIRA, S. Contribuição ao conhecimento da estratigrafia e paleontologia do Arenito Bauru. Bol. Inst. Geogr. Geol., São Paulo, Instituto de Geografia/USP (51):1-163, 1974.

OLIVEIRA, A.I. \& LEONARDOS, O.H. A Geologia do Brasil, $3^{\underline{a}}$ ed. Reeditada pela Esc.Sup.Agr. de Mossoró, Mossoró, Esc. Sup. Agr., V. LXXXII, 1978, (Coleçāo Mossoroense).

PRICE, L.I. Os crocodilídeos da fauna da Formaçāo Bauru do Cretáceo terrestre do BrasI Meridional. An.Acad.Bras.Ciênc., Rio de Janeiro, Ac.Bras.Ciênc., 22(4):473-490, 1950a.

PRICE, L.I. On a new Crocodilian Sphagaesaurus from Cretaceous of the State of São Paulo, Brazil.An.Acad.Bras.Ciênc., Rio de Janeiro, Acad.Bras.Ciênc., 22(1):77-83, 1950b.

PRICE, L.I. Os quelônios da Formaçāo Bauru, cretáceo terrestre do Brasil Meirdional. Bol. DGM/DNPM Rio de Janeiro, DGM/DNPM, (147):1-39, 1953.

PRICE, L.I. Novos crocodilíferos dos Arenitos da Série Bauru, Cretáceo do Estado de Minas Gerais. An.Acad.Bras.Ciênc., Rio de Janeiro, Ac.Bras.Ciênc. 27(4):487-498, 1957.

SAD, J.H.G.; CARDOSO, R.N.; COSTA, M.T. Formaçōes Cretácicas em Minas Gerais; uma revisāo Rev.Bras.Geoc., São Paulo, SBG, $1(1): 2-13,1971$.

SOARES, P.C. Estratigrafia das Formaçōes Jurássico-Cretáceas na Bacia do Paraná, Brasil. Comité Sudamericano del Jurássico y Cretáceo: Cuencas sedimentares del Jurássico y Cretácico de America del Sur, v.1: 271 - 304. Buenos Aires, 1981.

SOARES, P.C. \& LANDIM, P.M.B. Comparison between the tectonic evolution of the intracratonic and marginal basins in south Brasil. An.Acad.Bras. Ciênc., Rio de Janeiro, Ac. Bras. Ciênc. (48):313-324, 1975 (suplemento) 
SOARES,P.C.; LANDIM,P.M.B.; FULFARO, V.J.; SOBREIRO NETO, A.F. Ensaio de caracterização estratigráfica do cretáceo no Estado de São Paulo: Grupo Bauru. Rev.Bras.Geoc., Sāo Paulo, SBG, 10(3):177185, 1979.

SUGUIO, K. Formação Bauru: Calcários e sedimentos detríticos associados. São Paulo, Instituto de Geociências/USP, 2v.,1973 (Tese de Livre Docência).

SUGUIO, K. Fatores Paleoambientais e paleoclimáticos e subdivisão estratigráfica do Grupo Bauru.In: MESA REDONDA: A Formaçāo Bauru no Estado de São Paulo e Regiōes Adjacentes, Coletânea de trabalhose debates. São Paulo, SBG, 1980, p. 15-30 (Publicação especial, 7).

SUGUIO, K. \& BARCELOS, J.H. - 1978 - Nota sobre a ocorrência de atapulgita em sedimentos do Grupo Bauru, Cretáceo Superior da Bacia do Paraná. In: Anais do XXX Congresso Brasileiro de Geologia, vol.3, Recife, BBG, 1978, p.1170-1179.

SUGUIO, K. \& BARCELOS, J.H. Calcretes of the Bauru Group (Cretaceous) Brazil: Petrology and Geological Significance. Boletim do Instituto de Geociências, São Paulo, Instituto de Geociências, USP, (14):31-47, 1983.

SUGUIO, K.; BARCELOS, J.H.; MATSUI, E. Significados paleoclimáticos e paleoambientais das rochas calcárias da Formação Caatinga (Ba) e do Grupo Bauru (Mg/SP). In: Anais do XXXI Congresso Brasileiro de Geologia, Vol. I, Camboriú, SBG, 1980, p. 607-616.

SUGUIO, K. \& COIMBRA, A.M. Madeira fóssil solidificada na Formaçāo Botucatu. Ciência e Cultura, Sāo Paulo, SBPC, 24(11):1049-1055, 1972.

SUGUIO, K.; FULFARO, J.V.; AMARAL, G.; GUIDORZI, L.A. Comportamentos estratigráfico e estrutural da Formaçāo Bauru nas Regiōes Administrativas 7 (Bauru), 8 (São José do Rio Preto) e 9 (Araçatuba) no Estado de São Paulo. In: Atas do Simpósio Regional de Geologia, vol.1, Sāo Paulo, SBG., 1977, p.231-244.

SUGUIO, K.; SVISERO, D.P.; FELITTI FILHO, W Conglomerados polimíticos diamantíferos de idade cretácica de Romaria (MG): um exemplo de sedimentação de leques aluviais. In: Atas do Simpósio Regional de Geologia, 2, Rio Claro, SBG, v.1:217-229, 1979. 